\title{
Determinants of Resting Oxidative Stress in Middle-Aged and Elderly Men and Women: WASEDA'S Health Study
}

\author{
Takuji Kawamura $\mathbb{D}^{\mathbb{D}},{ }^{1}$ Kumpei Tanisawa, ${ }^{2}$ Ryoko Kawakami $\mathbb{D}^{2}{ }^{2}$ Chiyoko Usui, ${ }^{2}$ \\ Tomoko Ito, ${ }^{1}$ Hiroki Tabata, ${ }^{1,3}$ Nobuhiro Nakamura, ${ }^{2}$ Sayaka Kurosawa, ${ }^{4}$ Wonjun Choi, ${ }^{5}$ \\ Sihui Ma, ${ }^{2,6}$ Zsolt Radak, ${ }^{2,7}$ Susumu S. Sawada, ${ }^{2}$ Katsuhiko Suzuki, ${ }^{2}$ Kaori Ishii, ${ }^{2}$ \\ Shizuo Sakamoto, ${ }^{2}$ Koichiro Oka, ${ }^{2}$ Mitsuru Higuchi, ${ }^{2}$ and Isao Muraoka ${ }^{2}$ \\ ${ }^{1}$ Waseda Institute for Sport Sciences, 2-579-15 Mikajima, Tokorozawa, Saitama 359-1192, Japan \\ ${ }^{2}$ Faculty of Sport Sciences, Waseda University, 2-579-15 Mikajima, Tokorozawa, Saitama 359-1192, Japan \\ ${ }^{3}$ Sportology Center, Juntendo University Graduate School of Medicine, 2-15-8 Hongo, Bunkyo-ku, Tokyo, Japan \\ ${ }^{4}$ Institute of Advanced Active Aging Research, Waseda University, 2-579-15 Mikajima, Tokorozawa, Saitama 359-1192, Japan \\ ${ }^{5}$ Graduate School of Sport Sciences, Waseda University, 2-579-15 Mikajima, Tokorozawa, Saitama 359-1192, Japan \\ ${ }^{6}$ Research Fellow of Japan Society for the Promotion of Sciences, 5-3-1, Kojimachi, Chiyoda-ku, Tokyo 102-0083, Japan \\ ${ }^{7}$ Research Center for Molecular Exercise Science, University of Physical Education, Alkotas Str. 44, Budapest 1123, Hungary
}

Correspondence should be addressed to Takuji Kawamura; t.kawamura2@kurenai.waseda.jp

Received 25 February 2021; Accepted 10 May 2021; Published 8 June 2021

Academic Editor: Marcio Carocho

Copyright (c) 2021 Takuji Kawamura et al. This is an open access article distributed under the Creative Commons Attribution License, which permits unrestricted use, distribution, and reproduction in any medium, provided the original work is properly cited.

\begin{abstract}
Previous studies have not investigated the determinants of resting oxidative stress, including physical fitness, as it relates to redox regulation. The present study therefore was aimed at identifying lifestyle and biological factors that determine resting oxidative stress, including objectively measured physical fitness. In 873 middle-aged and elderly men and women, age and anthropometric parameters, lifestyle-related parameters, medication and supplementation status, physical fitness, biochemical parameters, and nutritional intake status, as well as three plasma oxidative stress markers: protein carbonyl $(\mathrm{PC}), \mathrm{F}_{2}$-isoprostane $\left(\mathrm{F}_{2}\right.$-IsoP), and thiobarbituric acid reactive substances (TBARS), were surveyed and measured. The determinants of PC, $\mathrm{F}_{2}$-IsoP, and TBARS in all participants were investigated using stepwise multiple regression analysis. In $\mathrm{PC}$, age $(\beta=-0.11, P=0.002)$, leg extension power $(\beta=-0.12, P=0.008)$, BMI $(\beta=0.12, P=0.004)$, and HDL-C $(\beta=0.08, P=0.040)$ were included in the regression model (adjusted $\left.R^{2}=0.018\right)$. In the $\mathrm{F}_{2}$-IsoP, smoking status $(\beta=0.07, P=0.060)$, BMI $(\beta=0.07, P=0.054)$, and $\mathrm{HbA1c}(\beta=-0.06, P$ $=0.089)$ were included in the regression model (adjusted $\left.R^{2}=0.006\right)$. In TBARS, glucose $(\beta=0.18, P<0.001), \operatorname{CRF}(\beta=0.16, P$ $<0.001)$, age $(\beta=0.15, P<0.001)$, TG $(\beta=0.11, P=0.001)$, antioxidant supplementation $(\beta=0.10, P=0.002)$, and HbA1c $(\beta=-0.13, P=0.004)$ were included in the regression model (adjusted $\left.R^{2}=0.071\right)$. In conclusion, the present study showed that age, anthropometric index, lifestyle-related parameters, medication and supplementation status, objectively measured physical fitness, biochemical parameters, and nutritional intake status explain less than $10 \%$ of oxidative stress at rest.
\end{abstract}

\section{Introduction}

Humans and many other organisms take in oxygen, which is present in approximately $21 \%$ of the atmosphere, and use it to survive. However, during normal metabolic processes that utilise oxygen for the synthesis of ATP, some oxygen is converted into reactive oxygen species (ROS) such as superoxide, hydrogen peroxide, and hydroxyl radicals. Moderate ROS play an essential role in maintaining physiological homeostasis, including cellular proliferation and host defense [1], but excess ROS beyond the antioxidant systems of the organism give rise to oxidative stress [2]. With the development of free radical research over the past 60 years, it has become widely recognised that excessive and chronic oxidative stress is 
implicated in various pathological conditions such as cardiovascular diseases, cancer, neurodegenerative diseases, diabetes, and aging [3]. Therefore, maintaining the oxidationreduction (redox) balance within an optimal range is crucial for the survival and health of an organism. To optimise the redox balance, it is necessary to identify lifestyle and biological factors that determine the levels of oxidative stress at rest.

In human studies, lifestyle and biological variables positively related to resting oxidative stress include alcohol consumption [4], smoking [4, 5], obesity [5-7], and aging [8, 9], as well as disease development [3]. On the other hand, variables that are negatively related to resting oxidative stress include calorie restriction [10], intake of antioxidants from food [5], antioxidant supplementation (e.g., vitamin C and vitamin E) [10], and anti-inflammatory medication [11]. In addition to these variables, gender has been suggested to be associated with resting oxidative stress, although no consensus has yet been reached $[4,5]$. As such, many lifestyle and biological variables have been reported to potentially influence the regulation of resting oxidative stress; more importantly, the degree of influence of each variable on resting oxidative stress should be assessed comprehensively rather than separately. Indeed, several previous studies have explored the determinants of resting oxidative stress using multiple lifestyle and biological variables, such as age, sex, smoking status, and biochemical parameters [4-7, 12-14]. However, only one previous study has explored variables related to physical fitness, which are thought to be negatively related to oxidative stress [4]. In addition, as this previous study used broadly categorised exercise frequency as an independent variable, it is not clear whether objectively measured physical fitness can be a determinant of resting oxidative stress.

Therefore, the purpose of this study was to identify the lifestyle and biological variables that determine resting oxidative stress, including objectively measured physical fitness. For this purpose, two widely used and relatively reliable markers of oxidative stress $[15,16]$, protein carbonyl (PC) and $\mathrm{F}_{2}$-isoprostane $\left(\mathrm{F}_{2}\right.$-IsoP), were measured spectrophotometrically using plasma samples from 873 participants of the WASEDA'S Health Study (Waseda Alumni's Sports, Exercise, Daily Activity, Sedentariness, and Health Study). In addition, thiobarbituric acid reactive substances (TBARS), which are now often criticised [17], were included in the analysis for comparison with data from previous studies. Along with these three markers of oxidative stress, a wide range of surveys and measurements were conducted, including objectively measured physical fitness, sex, age, anthropometric index, lifestyle-related parameters, medication and antioxidant supplementation status, biochemical parameters, and nutritional intake status. Through these measurements, the present study was aimed at providing evidence for establishing preventive strategies to avoid chronic oxidative stress.

\section{Materials and Methods}

2.1. Participants. This cross-sectional study used baseline data from the WASEDA'S Health Study. The WASEDA'S Health Study is a cohort study that investigates the relation- ship between health outcomes and sports, exercise, physical activity, and sedentary behaviour among alumni of Waseda University and their spouses aged 40 years or older.

The WASEDA'S Health Study consisted of four cohorts (Cohorts A-D). Participants in Cohort A completed an internet-based self-administered questionnaire on physical activity and health outcomes. Participants in Cohort B were asked to complete a self-administered questionnaire, as well as utilise an accelerometer to measure physical activity and sedentary time. Participants in Cohort C completed several medical tests in addition to the items in Cohort B. Participants in Cohort D performed a physical fitness test and detailed medical tests in addition to the items in Cohort C. Participants in the present study reported here were participants from Cohort D of the WASEDA'S Health Study.

The study included 1040 participants who took part in Cohort D in the WASEDA'S Health Study between March 2015 and July 2018. To perform an appropriate analysis, several inclusion and exclusion criteria were established in this study. First, those with missing data for any of the variables used in the study were excluded $(n=111)$. Second, those who consumed food on the morning of the measurement $(n=7)$, those who had heart diseases $(n=41)$, and those who met the exclusion criteria for calculating energy intake on the brief-type self-administered dietary history questionnaire (BDHQ) $(n=8)$ were excluded from the analysis. As a result of the exclusion and inclusion criteria, 873 individuals (296 women and 577 men) were ultimately included in the analysis of this study (Figure 1).

The participants were briefed on the study and signed an informed consent form prior to the baseline survey. This study was approved by the Research Ethics Committee of Waseda University (approval number: 2014-G002). The study was conducted in accordance with the Declaration of Helsinki (1964).

2.2. Questionnaire Survey. Self-administered questionnaires were used to determine the following: sex (man or woman), age (in years), exercise habits (whether or not they exercise regularly), smoking habits (current, former, and nonsmoking), frequency of drinking (less than once a week, 1-2 times a week, 3-4 times a week, and more than 5 times a week), antioxidant supplementation status (yes/no), and antiinflammatory medication status (yes/no). BDHQ was also used to investigate energy intake (kcal/day), vitamin A (calculated as retinol activity equivalent) ( $\mu \mathrm{g} \mathrm{RAE} /$ day), vitamin $\mathrm{C}(\mathrm{mg} /$ day), $\alpha$-tocopherol (mg/day), and $\beta$-carotene (calculated as $\beta$-carotene equivalent) ( $\mu \mathrm{g} /$ day). The BDHQ was assessed for validity in previous studies $[18,19]$.

\subsection{Measurement of Physical Characteristics. Height $(\mathrm{cm})$} and weight $(\mathrm{kg})$ were measured using a stature meter (YHS-200D, YAGAMI Inc., Nagoya, Japan) and an anthropometer (MC-980A, Tanita, Tokyo, Japan). Weight measurements were taken with light clothing and with shoes off. Body mass index (BMI) $\left(\mathrm{kg} / \mathrm{m}^{2}\right)$ was calculated from height and weight measurements. Body fat percentage was measured using bioelectrical impedance analysis (MC-980A, Tanita, Tokyo, Japan). The lean body mass (LBM) (kg) was 


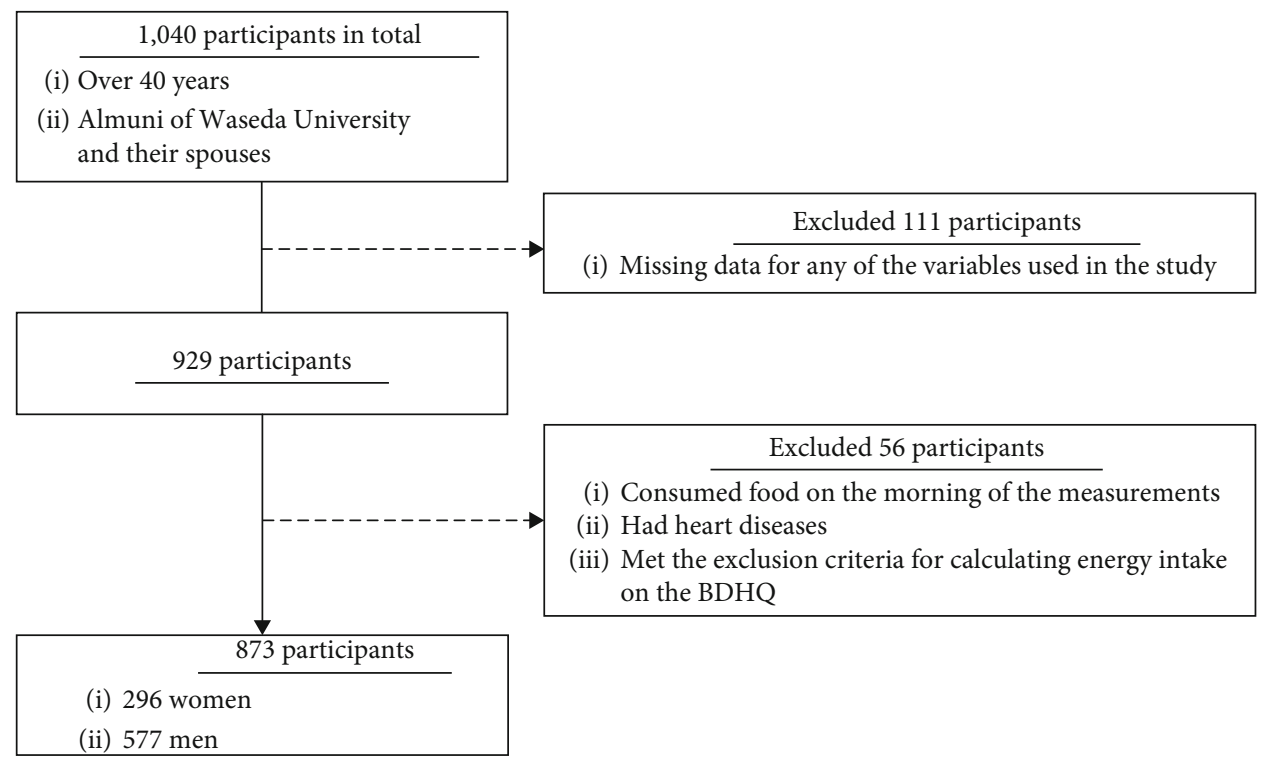

FIgURE 1: Selection and exclusion processes of the participants in the study.

calculated from the weight and body fat percentage. Visceral fat area (VFA) $\left(\mathrm{cm}^{2}\right)$ was measured at the umbilicus level, using magnetic resonance imaging (MRI) (SIGNA Premier, GE Healthcare, Waukesha, WI, USA), as described in a previous report [20].

2.4. Physical Fitness Tests. Cardiorespiratory fitness (CRF) $(\mathrm{mL} / \mathrm{kg} / \mathrm{min})$ was measured using a bicycle ergometer (828E, Monarch, Stockholm, Sweden), and after 3 min of resting electrocardiogram measurements (ML-9000 and MXL-1000, Fukuda Denshi, Tokyo, Japan), men and women started at $30 \mathrm{~W}$ and $15 \mathrm{~W}$, respectively, and the load was gradually increased by $15 \mathrm{~W}$ per minute until exhaustion. During each measurement, the oxygen and carbon dioxide concentrations in the exhaled gas were measured by the breath-by-breath method using an exhaled gas analyser with a mask for breath gas analysis (AE310S and AE100i, Minato Medical Science, Osaka, Japan). A blood pressure measurement cuff was wrapped around the left upper arm, and blood pressure $(\mathrm{mmHg})$ was measured using an automatic sphygmomanometer for exercise testing (Tango M2, SunTech Medical, Morrisville, NC, USA). Heart rate (bpm) and blood pressure before and during exercise were used as the safety controls. The endpoint of the exercise stress test was a plateau in oxygen uptake or until the heart rate reached approximately $90 \%$ of the predicted maximum age-specific heart rate. However, they stopped the exercise test if they reached a rating of perceived exertion (RPE) of 18 or higher, if they reported an inability to continue exercising, or if their systolic blood pressure reached $250 \mathrm{mmHg}$. Following the exercise period, the participants took a $1 \mathrm{~min}$ active recovery and 2 minutes of seated rest to complete the exercise test. The highest average oxygen uptake per $30 \mathrm{~s}$ during exercise was set as the $\dot{\mathrm{V}}_{2}$ peak. The leg extension power (W) was measured five times repeatedly using a recumbent leg press (Anaeropress 3500, Combi, Tokyo, Japan), and the maximum value was adopted.
2.5. Blood Sampling and Measurement of Oxidative Stress. The participants were instructed to fast from the night before blood collection. Venous blood was collected from the forearm vein after checking for breakfast skipping at the time of blood collection. Blood was collected into a blood collection tube (Terumo Inc., Tokyo, Japan) with an anticoagulant (Heparin $\mathrm{Na}$ or EDTA-2Na) or a tube without an anticoagulant and centrifuged at $4^{\circ} \mathrm{C}$ at $3000 \mathrm{rpm}$ for $10 \mathrm{~min}$ using a centrifuge (Model 5911, Kubota, Tokyo, Japan). The supernatant was transferred to microtubes, and both plasma and serum samples were stored in a freezer at $-80^{\circ} \mathrm{C}$ until analysis. Serum samples were analysed for lipid metabolism (total cholesterol (total-C, in $\mathrm{mg} / \mathrm{dL}$ ), HDL cholesterol (HDL-C, in $\mathrm{mg} / \mathrm{dL}$ ), $\mathrm{LDL}$ cholesterol (LDL-C, in $\mathrm{mg} / \mathrm{dL}$ ), triglycerides (TG, in $\mathrm{mg} / \mathrm{dL}$ )), and plasma samples were analysed for glucose metabolism (fasting blood glucose (glucose, in $\mathrm{mg} / \mathrm{dL}$ ) and haemoglobin Alc (HbAlc, in \%)). All analyses of these items were conducted by an external institution (BML Inc., Tokyo, Japan).

Oxidative stress markers in plasma were measured using commercially available protein carbonyl colorimetric assay kits, 8-isoprostane ELISA kits, and TBARS assay kits (Cayman Chemical, Ann Arbor, MI, USA). Oxidative stress measurements were performed between March and August 2020, and all results were calculated based on standard curves using standard solutions. The intra- and interassay CVs of each biomarker were $8.8 \%$ and $12.0 \%$ for PC (nmol $/ \mathrm{mg}$ protein), $6.4 \%$ and $8.0 \%$ for $\mathrm{F}_{2}$-IsoP $(\mathrm{pg} / \mathrm{mL})$, and $8.8 \%$ and $9.5 \%$ for TBARS $(\mu \mathrm{M})$, respectively, generally meeting the technical criteria proposed in a previous study [15].

2.6. Statistical Analysis. First, participants were classified by gender, and the physical characteristics and oxidative stress levels of each group were compared. The participants were also classified into tertiles for each oxidative stress marker, and the physical characteristics of each group were compared. For descriptive data, continuous variables are 
TABLE 1: Characteristics of the participants by gender.

\begin{tabular}{|c|c|c|c|}
\hline & $\begin{array}{c}\text { All } \\
(n=873)\end{array}$ & $\begin{array}{c}\text { Women } \\
(n=296)\end{array}$ & $\begin{array}{c}\text { Men } \\
(n=577)\end{array}$ \\
\hline \multicolumn{4}{|l|}{ Age and anthropometric index } \\
\hline Age (years) & $55 \pm 10$ & $52 \pm 9$ & $56 \pm 10$ \\
\hline BMI $\left(\mathrm{kg} / \mathrm{m}^{2}\right)$ & $22.9 \pm 3.1$ & $21.3 \pm 2.7$ & $23.7 \pm 3.0$ \\
\hline LBM (kg) & $48.8 \pm 9.0$ & $38.4 \pm 3.1$ & $54.2 \pm 5.4$ \\
\hline VFA $\left(\mathrm{cm}^{2}\right)$ & $75.2 \pm 42.3$ & $51.0 \pm 29.5$ & $87.6 \pm 42.5$ \\
\hline \multicolumn{4}{|l|}{ Lifestyle-related parameters } \\
\hline Exercise habits $(n, \%)$ & $300(34.4)$ & $114(38.5)$ & $186(32.2)$ \\
\hline Smokers $(n, \%)$ & $54(6.2)$ & $7(2.4)$ & $47(8.1)$ \\
\hline Nondrinker $(n, \%)$ & $177(20.4)$ & $102(24.3)$ & $75(18.4)$ \\
\hline \multicolumn{4}{|l|}{ Medication and supplementation status } \\
\hline Antioxidant supplementation $(n, \%)$ & $116(13.3)$ & $49(16.6)$ & $67(11.6)$ \\
\hline Anti-inflammatory medication $(n, \%)$ & $31(3.6)$ & $14(4.7)$ & $17(2.9)$ \\
\hline \multicolumn{4}{|l|}{ Physical fitness } \\
\hline Leg extension power $(\mathrm{W})$ & $1083 \pm 425$ & $701 \pm 222$ & $1279 \pm 367$ \\
\hline $\mathrm{CRF}(\mathrm{mL} / \mathrm{kg} / \mathrm{min})$ & $28.8 \pm 6.3$ & $26.0 \pm 5.1$ & $30.2 \pm 6.3$ \\
\hline \multicolumn{4}{|l|}{ Biochemical parameters } \\
\hline Total-C (mg/dL) & $211 \pm 36$ & $214 \pm 38$ & $209 \pm 35$ \\
\hline HDL-C (mg/dL) & $66 \pm 17$ & $74 \pm 16$ & $62 \pm 16$ \\
\hline LDL-C (mg/dL) & $121 \pm 31$ & $118 \pm 33$ & $122 \pm 30$ \\
\hline $\mathrm{TG}(\mathrm{mg} / \mathrm{dL})$ & $99 \pm 79$ & $75 \pm 42$ & $111 \pm 90$ \\
\hline Glucose (mg/dL) & $96 \pm 14$ & $90 \pm 9$ & $98 \pm 15$ \\
\hline HbAlc (\%) & $5.4 \pm 0.4$ & $5.3 \pm 0.4$ & $5.5 \pm 0.5$ \\
\hline \multicolumn{4}{|l|}{ Nutritional intake status } \\
\hline Energy intake (kcal/day) & $1973 \pm 526$ & $1758 \pm 448$ & $2082 \pm 529$ \\
\hline Vitamin A ( $\mu \mathrm{g}$ RAE/day) & $930 \pm 496$ & $888 \pm 457$ & $952 \pm 514$ \\
\hline Vitamin C (mg/day) & $131 \pm 63$ & $135 \pm 63$ & $129 \pm 62$ \\
\hline$\alpha$-Tocopherol (mg/day) & $8.5 \pm 3.0$ & $8.3 \pm 3.0$ & $8.6 \pm 3.0$ \\
\hline$\beta$-Carotene ( $\mu \mathrm{g} /$ day) & $4467 \pm 2852$ & $5065 \pm 3046$ & $4159 \pm 2699$ \\
\hline
\end{tabular}

Data for continuous variables are presented as the mean \pm standard deviation (SD), and data for categorical variables are presented as the number of persons $(n)$ and percentage (\%) of applicable persons. BMI: body mass index; LBM: lean body mass; VFA: visceral fat area; CRF: cardiorespiratory fitness; total-C: total cholesterol; HDL-C: HDL cholesterol; LDL-C: low-density lipoprotein cholesterol; TG: triglycerides; glucose: fasting blood glucose; HbA1c: haemoglobin Alc; vitamin A: retinol activity equivalent; $\beta$-carotene: $\beta$-carotene equivalent.

TABLE 2: Resting oxidative stress levels of the participants.

\begin{tabular}{lccc}
\hline & $\begin{array}{c}\text { All } \\
(n=873)\end{array}$ & $\begin{array}{c}\text { Women } \\
(n=296)\end{array}$ & $\begin{array}{c}\text { Men } \\
(n=577)\end{array}$ \\
\hline PC $(\mathrm{nmol} / \mathrm{mg}$ protein $)$ & $1.8 \pm 0.9$ & $1.9 \pm 1.0$ & $1.7 \pm 0.8$ \\
$\mathrm{~F}_{2}$-IsoP $(\mathrm{pg} / \mathrm{mL})$ & $38.8 \pm 31.6$ & $41.1 \pm 32.7$ & $37.6 \pm 31.0$ \\
TBARS $(\mu \mathrm{M})$ & $2.5 \pm 0.6$ & $2.3 \pm 0.6$ & $2.6 \pm 0.6$ \\
\hline
\end{tabular}

Data are presented as means \pm standard deviation (SD). PC: protein carbonyl; $\mathrm{F}_{2}$-IsoP: $\mathrm{F}_{2}$-isoprostane; TBARS: thiobarbituric acid reactive substances.

presented as mean \pm standard deviation, and categorical variables are presented as the number of persons and percentages. Three multiple regression models were developed to identify the determinants of each oxidative stress marker, and the standard partial regression coefficients and 95\% confidence intervals for the independent variables were calculated.

The dependent variables in each model were PC, $\mathrm{F}_{2}$-IsoP, and TBARS. The candidate independent variables in each model were age (years), BMI $\left(\mathrm{kg} / \mathrm{m}^{2}\right)$, LBM $(\mathrm{kg})$, VFA $\left(\mathrm{cm}^{2}\right)$, exercise habits (yes or no), smoking status (yes or no), drinking status (yes or no), antioxidant supplementation status (yes or no), anti-inflammatory medication status (yes or no), leg extension power (W), CRF ( $\mathrm{mL} / \mathrm{kg} / \mathrm{min})$, total cholesterol (mg/dL), HDL-C (mg/dL), LDL-C (mg/dL), TG $(\mathrm{mg} / \mathrm{dL})$, glucose $(\mathrm{mg} / \mathrm{dL}), \mathrm{HbAlc}(\%)$, energy intake (kcal/day), vitamin A ( $\mu \mathrm{g}$ RAE/day), vitamin $\mathrm{C}$ (mg/day), $\alpha$ tocopherol (mg/day), and $\beta$-carotene equivalent ( $\mu \mathrm{g} /$ day). The stepwise method was used to develop the model, and 
TABLE 3: Characteristics of the participants by protein carbonyl tertiles.

\begin{tabular}{|c|c|c|c|}
\hline & $\begin{array}{c}\mathrm{T} 1 \\
(n=291)\end{array}$ & $\begin{array}{c}\mathrm{T} 2 \\
(n=291)\end{array}$ & $\begin{array}{c}\mathrm{T} 3 \\
(n=291)\end{array}$ \\
\hline \multicolumn{4}{|l|}{ Age and anthropometric parameters } \\
\hline Age (years) & $56 \pm 10$ & $55 \pm 9$ & $53 \pm 9$ \\
\hline BMI $\left(\mathrm{kg} / \mathrm{m}^{2}\right)$ & $22.9 \pm 3.2$ & $22.8 \pm 3.0$ & $23.0 \pm 3.2$ \\
\hline LBM (kg) & $49.0 \pm 8.5$ & $48.9 \pm 8.9$ & $48.6 \pm 9.4$ \\
\hline VFA $\left(\mathrm{cm}^{2}\right)$ & $73.4 \pm 43.4$ & $75.7 \pm 42.7$ & $76.5 \pm 40.9$ \\
\hline \multicolumn{4}{|l|}{ Lifestyle-related parameters } \\
\hline Exercise habits $(n, \%)$ & $197(67.7)$ & $191(65.6)$ & $185(63.6)$ \\
\hline Smokers $(n, \%)$ & $18(6.2)$ & $19(6.5)$ & $17(5.8)$ \\
\hline Nondrinker $(n, \%)$ & $55(18.9)$ & $67(23.0)$ & $55(18.9)$ \\
\hline \multicolumn{4}{|l|}{ Medication and supplementation status } \\
\hline Antioxidant supplementation $(n, \%)$ & $43(14.8)$ & $34(11.7)$ & $39(13.4)$ \\
\hline Anti-inflammatory medication $(n, \%)$ & $10(3.4)$ & $11(3.8)$ & $10(3.4)$ \\
\hline \multicolumn{4}{|l|}{ Physical fitness } \\
\hline Leg extension power $(\mathrm{W})$ & $1093 \pm 419$ & $1096 \pm 437$ & $1059 \pm 419$ \\
\hline $\mathrm{CRF}(\mathrm{mL} / \mathrm{kg} / \mathrm{min})$ & $29.2 \pm 6.7$ & $28.6 \pm 6.1$ & $28.6 \pm 5.9$ \\
\hline \multicolumn{4}{|l|}{ Biochemical parameters } \\
\hline Total-C (mg/dL) & $210 \pm 36$ & $210 \pm 35$ & $212 \pm 38$ \\
\hline HDL-C (mg/dL) & $66 \pm 17$ & $64 \pm 17$ & $68 \pm 17$ \\
\hline $\mathrm{LDL}-\mathrm{C}(\mathrm{mg} / \mathrm{dL})$ & $119 \pm 33$ & $122 \pm 30$ & $121 \pm 32$ \\
\hline $\mathrm{TG}(\mathrm{mg} / \mathrm{dL})$ & $99 \pm 68$ & $101 \pm 102$ & $96 \pm 61$ \\
\hline Glucose (mg/dL) & $96 \pm 13$ & $95 \pm 13$ & $96 \pm 14$ \\
\hline HbAlc (\%) & $5.4 \pm 0.5$ & $5.4 \pm 0.4$ & $5.4 \pm 0.4$ \\
\hline \multicolumn{4}{|l|}{ Nutritional intake status } \\
\hline Energy intake (kcal/day) & $1997 \pm 553$ & $1955 \pm 503$ & $1967 \pm 522$ \\
\hline Vitamin A ( $\mu \mathrm{g}$ RAE/day) & $899 \pm 478$ & $965 \pm 490$ & $926 \pm 518$ \\
\hline Vitamin C (mg/day) & $132 \pm 62$ & $133 \pm 63$ & $127 \pm 62$ \\
\hline$\alpha$-Tocopherol (mg/day) & $8.6 \pm 3.1$ & $8.4 \pm 2.9$ & $8.4 \pm 2.0$ \\
\hline$\beta$-Carotene ( $\mu \mathrm{g} /$ day $)$ & $4483 \pm 2827$ & $4675 \pm 3009$ & $4242 \pm 2706$ \\
\hline
\end{tabular}

Data for continuous variables are presented as the mean \pm standard deviation (SD), and data for categorical variables are presented as the number of persons $(n)$ and percentage (\%). BMI: body mass index; LBM: lean body mass; VFA: visceral fat area; CRF: cardiorespiratory fitness; total-C: total cholesterol; HDL-C: HDL cholesterol; LDL-C: low-density lipoprotein cholesterol; TG: triglycerides; glucose: fasting blood glucose; HbA1c: haemoglobin A1c; vitamin A: retinol activity equivalent; $\beta$-carotene: $\beta$-carotene equivalent.

the forward selection method was used as a variable selection method. Before using the stepwise method, the variance inflation factor for each variable was calculated to avoid multicollinearity and to ensure that the VIF was less than 10. The probability for being stepwise was set to 0.10 , for the $P$ value at the time of input, and 0.15 , for the $P$ value at the time of removal. Although VFA was used as a measure of obesity in this study, the analyses were conducted using body fat percentage instead of VFA as a sensitivity analysis. Since this study was exploratory, the increase in alpha error due to multiple comparisons was not considered, and statistical significance was expressed when the two-sided $P$ value was less than $5 \%$. All statistical analyses were performed using SPSS Statistics version 26 (IBM Corporation, Chicago, IL, USA).

\section{Results}

3.1. Characteristics of the Participants. The characteristics of all participants and participants by sex are presented in Table 1. The overall number of participants in this study was 873 , of which 296 were women and 577 were men.

3.2. Resting Oxidative Stress Levels of the Participants. The resting oxidative stress levels of the participants are presented in Table 2. Participant characteristics by tertiles for each oxidative stress marker are shown in Tables 3-5.

3.3. Stepwise Multiple Regression Analysis of Each Oxidative Stress Marker in All Participants. The results of the stepwise multiple regression analysis of each oxidative stress marker 
TABLE 4: Characteristics of the participants by $\mathrm{F}_{2}$-isoprostane tertiles.

\begin{tabular}{|c|c|c|c|}
\hline & $\begin{array}{c}\mathrm{T} 1 \\
(n=291)\end{array}$ & $\begin{array}{c}\mathrm{T} 2 \\
(n=291)\end{array}$ & $\begin{array}{c}\text { T3 } \\
(n=291)\end{array}$ \\
\hline \multicolumn{4}{|l|}{ Age and anthropometric parameters } \\
\hline Age (years) & $54 \pm 9$ & $55 \pm 10$ & $54 \pm 10$ \\
\hline BMI $\left(\mathrm{kg} / \mathrm{m}^{2}\right)$ & $22.6 \pm 2.9$ & $22.9 \pm 2.8$ & $23.1 \pm 3.6$ \\
\hline LBM (kg) & $48.8 \pm 8.7$ & $49.4 \pm 8.7$ & $48.3 \pm 9.3$ \\
\hline VFA $\left(\mathrm{cm}^{2}\right)$ & $71.7 \pm 37.3$ & $79.4 \pm 45.0$ & $74.4 \pm 43.9$ \\
\hline \multicolumn{4}{|l|}{ Lifestyle-related parameters } \\
\hline Exercise habits $(n, \%)$ & $190(65.3)$ & $194(66.7)$ & $189(64.9)$ \\
\hline Smokers $(n, \%)$ & $21(7.2)$ & $14(4.8)$ & $19(6.5)$ \\
\hline Nondrinker $(n, \%)$ & $65(22.3)$ & $49(16.8)$ & $63(21.6)$ \\
\hline \multicolumn{4}{|l|}{ Medication and supplementation status } \\
\hline Antioxidant supplementation $(n, \%)$ & $47(16.2)$ & $33(11.3)$ & $36(12.4)$ \\
\hline Anti-inflammatory medication $(n, \%)$ & $16(5.5)$ & $4(1.4)$ & $11(3.8)$ \\
\hline \multicolumn{4}{|l|}{ Physical fitness } \\
\hline Leg extension power $(\mathrm{W})$ & $1090 \pm 434$ & $1090 \pm 413$ & $1068 \pm 428$ \\
\hline $\mathrm{CRF}(\mathrm{mL} / \mathrm{kg} / \mathrm{min})$ & $29.4 \pm 6.1$ & $28.4 \pm 6.4$ & $28.5 \pm 6.3$ \\
\hline \multicolumn{4}{|l|}{ Biochemical parameters } \\
\hline Total-C (mg/dL) & $211 \pm 37$ & $209 \pm 34$ & $212 \pm 38$ \\
\hline HDL-C (mg/dL) & $67 \pm 18$ & $65 \pm 17$ & $67 \pm 17$ \\
\hline LDL-C (mg/dL) & $121 \pm 34$ & $120 \pm 29$ & $121 \pm 32$ \\
\hline $\mathrm{TG}(\mathrm{mg} / \mathrm{dL})$ & $95 \pm 58$ & $102 \pm 101$ & $99 \pm 72$ \\
\hline Glucose (mg/dL) & $96 \pm 12$ & $96 \pm 16$ & $95 \pm 12$ \\
\hline HbAlc (\%) & $5.5 \pm 0.4$ & $5.4 \pm 0.5$ & $5.4 \pm 0.4$ \\
\hline \multicolumn{4}{|l|}{ Nutritional intake status } \\
\hline Energy intake (kcal/day) & $1967 \pm 536$ & $1980 \pm 520$ & $1971 \pm 524$ \\
\hline Vitamin A ( $\mu \mathrm{g}$ RAE/day) & $133 \pm 60$ & $127 \pm 61$ & $132 \pm 67$ \\
\hline Vitamin C (mg/day) & $8.6 \pm 3.1$ & $8.2 \pm 2.8$ & $8.6 \pm 3.0$ \\
\hline$\alpha$-Tocopherol (mg/day) & $4721 \pm 3041$ & $4161 \pm 2606$ & $4518 \pm 2874$ \\
\hline$\beta$-Carotene ( $\mu \mathrm{g} /$ day) & $949 \pm 460$ & $910 \pm 515$ & $932 \pm 512$ \\
\hline
\end{tabular}

Data for continuous variables are presented as the mean \pm standard deviation (SD), and data for categorical variables are presented as the number of persons $(n)$ and percentage (\%). BMI: body mass index; LBM: lean body mass; VFA: visceral fat area; CRF: cardiorespiratory fitness; total-C: total cholesterol; HDL-C: HDL cholesterol; LDL-C: low-density lipoprotein cholesterol; TG: triglycerides; glucose: fasting blood glucose; HbA1c: haemoglobin Alc; vitamin A: retinol activity equivalent; $\beta$-carotene: $\beta$-carotene equivalent.

are presented in Table 6. With PC as the dependent variable, age $(\beta=-0.11, P=0.002)$, leg extension power $(\beta=-0.12$, $P=0.008)$, BMI $(\beta=0.12, P=0.004)$, and HDL-C $(\beta=0.08$ , $P=0.040$ ) were included in the regression model (adjusted $\left.R^{2}=0.018\right)$. In the $\mathrm{F}_{2}$-IsoP, smoking status $(\beta=0.07, P=$ $0.060)$, BMI $(\beta=0.07, P=0.054)$, and HbAlc $(\beta=-0.06, P$ $=0.089$ ) were included in the regression model (adjusted $\left.R^{2}=0.006\right)$. In TBARS, glucose $(\beta=0.18, P<0.001)$, CRF $(\beta=0.16, \quad P<0.001), \quad$ age $\quad(\beta=0.15, \quad P<0.001), \quad$ TG $(\beta=0.11, \quad P=0.001), \quad$ antioxidant supplementation $(\beta=0.10, P=0.002)$, and HbAlc $(\beta=-0.13, P=0.004)$ were included in the regression model (adjusted $R^{2}=0.071$ ).

3.4. Stepwise Multiple Regression Analysis of Each Oxidative Stress Marker in Men and Women. The results of the multiple regression analysis of each oxidative stress marker in women are presented in Table 7. With PC as the dependent variable, anti-inflammatory medication $(\beta=-0.12, P=0.044)$ was included in the regression model (adjusted $R^{2}=0.010$ ). In the $\mathrm{F}_{2}$-IsoP, smoking status $(\beta=0.16, P=0.005)$, BMI $(\beta=0.14, \quad P=0.016), \quad$ antioxidant supplementation $(\beta=-0.11, P=0.050)$, and energy intake $(\beta=0.10, P=$ 0.078 ) were included in the regression model (adjusted $R^{2}$ $=0.052)$. In TBARS, $\alpha$-tocopherol $(\beta=0.27, P=0.003), \beta$ carotene $(\beta=-0.24, P=0.008), \operatorname{CRF}(\beta=0.23, P<0.001)$, age $(\beta=0.25, P<0.001)$, HbAlc $(\beta=-0.14, P=0.033)$, anti-inflammatory medication $(\beta=0.13, P=0.017)$, and leg extension power $(\beta=-0.16, P=0.006)$ were included in the regression model (adjusted $R^{2}=0.090$ ). The results of the multiple regression analysis of each oxidative stress marker 
TABLE 5: Characteristics of the participants by thiobarbituric acid reactive substance tertiles.

\begin{tabular}{|c|c|c|c|}
\hline & $\begin{array}{c}\mathrm{T} 1 \\
(n=291)\end{array}$ & $\begin{array}{c}\mathrm{T} 2 \\
(n=291)\end{array}$ & $\begin{array}{c}\mathrm{T} 3 \\
(n=291)\end{array}$ \\
\hline \multicolumn{4}{|l|}{ Age and anthropometric parameters } \\
\hline Age (years) & $53 \pm 9$ & $55 \pm 10$ & $55 \pm 9$ \\
\hline BMI $\left(\mathrm{kg} / \mathrm{m}^{2}\right)$ & $22.7 \pm 3.3$ & $22.9 \pm 3.2$ & $23.0 \pm 2.9$ \\
\hline LBM (kg) & $47.2 \pm 9.0$ & $48.8 \pm 9.0$ & $50.5 \pm 8.3$ \\
\hline VFA $\left(\mathrm{cm}^{2}\right)$ & $72.2 \pm 42.5$ & $77.5 \pm 44.4$ & $75.9 \pm 40.0$ \\
\hline \multicolumn{4}{|l|}{ Lifestyle-related parameters } \\
\hline Exercise habits $(n, \%)$ & $182(62.3)$ & $197(67.9)$ & $194(66.7)$ \\
\hline Smokers $(n, \%)$ & $16(5.5)$ & $16(5.5)$ & $22(7.6)$ \\
\hline Nondrinker (\%) & $70(24.0)$ & $58(20.0)$ & $49(16.8)$ \\
\hline \multicolumn{4}{|l|}{ Medication and supplementation status } \\
\hline Antioxidant supplementation $(n, \%)$ & $30(10.3)$ & $37(12.8)$ & $49(16.8)$ \\
\hline Anti-inflammatory medication $(n, \%)$ & $7(2.4)$ & $13(4.5)$ & $11(3.8)$ \\
\hline \multicolumn{4}{|l|}{ Physical fitness } \\
\hline Leg extension power $(\mathrm{W})$ & $1028 \pm 406$ & $1068 \pm 438$ & $1152 \pm 423$ \\
\hline $\mathrm{CRF}(\mathrm{mL} / \mathrm{kg} / \mathrm{min})$ & $27.6 \pm 5.7$ & $28.9 \pm 6.3$ & $29.8 \pm 6.5$ \\
\hline \multicolumn{4}{|l|}{ Biochemical parameters } \\
\hline Total-C (mg/dL) & $205 \pm 36$ & $215 \pm 36$ & $211 \pm 36$ \\
\hline HDL-C (mg/dL) & $66 \pm 17$ & $67 \pm 17$ & $65 \pm 17$ \\
\hline $\mathrm{LDL}-\mathrm{C}(\mathrm{mg} / \mathrm{dL})$ & $117 \pm 31$ & $125 \pm 32$ & $121 \pm 31$ \\
\hline $\mathrm{TG}(\mathrm{mg} / \mathrm{dL})$ & $89 \pm 54$ & $101 \pm 67$ & $106 \pm 106$ \\
\hline Glucose (mg/dL) & $93 \pm 8.6$ & $96 \pm 13$ & $98 \pm 18$ \\
\hline HbAlc (\%) & $5.4 \pm 0.3$ & $5.4 \pm 0.5$ & $5.4 \pm 0.5$ \\
\hline \multicolumn{4}{|l|}{ Nutritional intake status } \\
\hline Energy intake (kcal/day) & $1922 \pm 515$ & $1973 \pm 525$ & $2024 \pm 535$ \\
\hline Vitamin A ( $\mu \mathrm{g}$ RAE/day) & $129 \pm 64$ & $132 \pm 63$ & $131 \pm 61$ \\
\hline Vitamin C (mg/day) & $8.3 \pm 3.0$ & $8.5 \pm 2.9$ & $8.6 \pm 3.1$ \\
\hline$\alpha$-Tocopherol (mg/day) & $4495 \pm 2891$ & $4482 \pm 2915$ & $4422 \pm 2757$ \\
\hline$\beta$-Carotene ( $\mu \mathrm{g} /$ day $)$ & $937 \pm 518$ & $907 \pm 472$ & $947 \pm 498$ \\
\hline
\end{tabular}

Data for continuous variables are presented as the mean \pm standard deviation (SD), and data for categorical variables are presented as the number of persons $(n)$ and percentage (\%). BMI: body mass index; LBM: lean body mass; VFA: visceral fat area; CRF: cardiorespiratory fitness; total-C: total cholesterol; HDL-C: HDL cholesterol; LDL-C: low-density lipoprotein cholesterol; TG: triglycerides; glucose: fasting blood glucose; HbA1c: haemoglobin A1c; vitamin A: retinol activity equivalent; $\beta$-carotene: $\beta$-carotene equivalent.

in men are presented in Table 8. With PC as the dependent variable, anti-inflammatory medication $(\beta=0.11, P=0.006$ ) , age $(\beta=-0.12, P=0.006)$, and visceral fat area $(\beta=0.08$, $P=0.046$ ) were included in the regression model (adjusted $\left.R^{2}=0.024\right)$. In the $\mathrm{F}_{2}$-IsoP, none of the variables were included in the regression model (adjusted $\left.R^{2}=0.033\right)$. Antioxidant supplementation $(\beta=0.12, P=0.003)$, TG $(\beta=0.13$, $P=0.002)$, glucose $(\beta=0.23, P<0.001)$, VFA $(\beta=-0.11, P$ $=0.011)$, and HbAlc $(\beta=-0.14, P=0.019)$ were included in the regression model (adjusted $R^{2}=0.056$ ).

\section{Discussion}

The present study explored lifestyle and biological variables that determine resting oxidative stress levels, including objectively measured physical fitness, in middle-aged and elderly men and women. As a result, several determinants were identified which may be related to the redox regulation of each oxidative stress marker. However, the variables selected in this study, such as age, anthropometric index, lifestylerelated parameters, medication and supplementation status, objectively measured physical fitness, biochemical parameters, and nutritional intake status, were very weakly associated with oxidative stress.

Although moderate oxidative stress is essential for homeostasis, excessive and chronic oxidative stress has been shown to be partially involved in the development and progression of various diseases and biological aging [3]. Thus, maintaining oxidative stress within an optimal range is expected to contribute to disease prevention and the extension of healthy life expectancy [21]. In this context, identifying and weighting the lifestyle and biological variables 
TABLE 6: Stepwise multiple regression analysis of each oxidative stress marker in all participants.

\begin{tabular}{|c|c|c|c|c|c|}
\hline & Partial regression coefficient & 95\% confidence interval & Standard partial regression coefficient & VIF & $P$ value \\
\hline \multicolumn{6}{|l|}{$P C^{* 1}$} \\
\hline Intercept & 1.518 & $0.795-2.242$ & & & $<0.001$ \\
\hline Age (years) & -0.010 & $-0.016--0.004$ & -0.11 & 1.10 & 0.002 \\
\hline Leg extension power $(\mathrm{W})$ & 0.000022 & $0.000-0.000$ & -0.12 & 1.38 & 0.008 \\
\hline BMI $\left(\mathrm{kg} / \mathrm{m}^{2}\right)$ & 0.034 & $0.011--0.057$ & 0.12 & 1.55 & 0.004 \\
\hline $\mathrm{HDL}-\mathrm{C}(\mathrm{mg} / \mathrm{dL})$ & 0.004 & $0.000-0.008$ & 0.08 & 1.34 & 0.040 \\
\hline \multicolumn{6}{|l|}{$F_{2}-I s o P * 2$} \\
\hline Intercept & 37.208 & $5.622-68.794$ & & & 0.021 \\
\hline Smokers & 3.403 & $-0.145-6.952$ & 0.07 & 1.07 & 0.060 \\
\hline $\mathrm{BMI}\left(\mathrm{kg} / \mathrm{m}^{2}\right)$ & 0.690 & $-0.013-1.393$ & 0.07 & 1.09 & 0.054 \\
\hline HbAlc (\%) & -4.185 & $-9.009-0.640$ & -0.06 & 1.05 & 0.089 \\
\hline \multicolumn{6}{|l|}{ TBARS *3 } \\
\hline Intercept & 1.634 & $1.055-2.213$ & & & $<0.001$ \\
\hline Glucose (mg/dL) & 0.008 & $0.004-0.012$ & 0.18 & 1.98 & $<0.001$ \\
\hline $\mathrm{CRF}(\mathrm{mL} / \mathrm{kg} / \mathrm{min})$ & 0.016 & $0.009-0.023$ & 0.16 & 1.15 & $<0.001$ \\
\hline Age (years) & 0.009 & $0.005-0.014$ & 0.15 & 1.29 & $<0.001$ \\
\hline $\mathrm{TG}(\mathrm{mg} / \mathrm{dL})$ & 0.001 & $0.000-0.001$ & 0.11 & 1.05 & 0.001 \\
\hline $\begin{array}{l}\text { Antioxidant } \\
\text { supplementation }\end{array}$ & 0.186 & $0.070-0.303$ & 0.10 & 1.01 & 0.002 \\
\hline HbAlc (\%) & 0.183 & $-0.308--0.057$ & -0.13 & 1.99 & 0.004 \\
\hline
\end{tabular}

VIF: variance inflation factor; PC: protein carbonyl; $\mathrm{F}_{2}$-IsoP: $\mathrm{F}_{2}$-isoprostane; TBARS: thiobarbituric acid reactive substances; LBM: lean body mass; BMI: body mass index; HDL-C: high-density lipoprotein cholesterol; HbAlc: haemoglobin Alc; glucose: fasting blood glucose; CRF: cardiorespiratory fitness; TG: triglycerides. ${ }^{* 1} R^{2}=0.022$, adjusted $R^{2}=0.018 ;{ }^{* 2} R^{2}=0.010$, adjusted $R^{2}=0.006 ;{ }^{* 3} R^{2}=0.077$, adjusted $R^{2}=0.071$.

TABLE 7: Stepwise multiple regression analysis of each oxidative stress marker in women.

\begin{tabular}{|c|c|c|c|c|c|}
\hline & $\begin{array}{c}\text { Partial regression } \\
\text { coefficient }\end{array}$ & $\begin{array}{l}95 \% \text { confidence } \\
\text { interval }\end{array}$ & $\begin{array}{c}\text { Standard partial regression } \\
\text { coefficient }\end{array}$ & VIF & $P$ value \\
\hline \multicolumn{6}{|l|}{$P C^{* 1}$} \\
\hline Intercept & 1.905 & $1.789-2.021$ & & & $<0.001$ \\
\hline $\begin{array}{l}\text { Anti-inflammatory } \\
\text { medication }\end{array}$ & -0.547 & $-1.080-0.015$ & -0.12 & 1.00 & 0.044 \\
\hline \multicolumn{6}{|l|}{$F_{2}-I s o P^{* 2}$} \\
\hline Intercept & -38.144 & $-80.099-3.810$ & & & 0.075 \\
\hline Smokers & 11.447 & $3.408-19.486$ & 0.16 & 1.03 & 0.005 \\
\hline BMI $\left(\mathrm{kg} / \mathrm{m}^{2}\right)$ & 1.690 & $0.312-3.068$ & 0.14 & 1.04 & 0.016 \\
\hline Antioxidant supplementation & -9.859 & $-19.724--0.006$ & -0.11 & 1.01 & 0.050 \\
\hline Energy intake (kcal/day) & 0.007 & $-0.001--0.016$ & 0.10 & 1.01 & 0.078 \\
\hline \multicolumn{6}{|l|}{ TBARS *3 } \\
\hline Intercept & 2.058 & $0.967-3.149$ & & & $<0.001$ \\
\hline$\alpha$-Tocopherol (mg/day) & 0.054 & $0.019-0.090$ & 0.27 & 2.71 & 0.003 \\
\hline$\beta$-Carotene ( $\mu \mathrm{g} /$ day $)$ & -4.556 & $0.000-0.000$ & -0.24 & 2.64 & 0.008 \\
\hline CRF (mL/kg/min) & 0.026 & $0.012-0.039$ & 0.23 & 1.23 & $<0.001$ \\
\hline Age (years) & 0.017 & $0.008-0.027$ & 0.25 & 1.65 & $<0.001$ \\
\hline HbAlc (\%) & -0.231 & $-0.443--0.019$ & -0.14 & 1.41 & 0.033 \\
\hline $\begin{array}{l}\text { Anti-inflammatory } \\
\text { medication }\end{array}$ & 0.362 & $0.065-0.659$ & 0.13 & 1.01 & 0.017 \\
\hline Leg extension power $(\mathrm{W})$ & 0.00004 & $-0.001-0.000$ & -0.16 & 1.11 & 0.006 \\
\hline
\end{tabular}

VIF: variance inflation factor; PC: protein carbonyl; $\mathrm{F}_{2}$-IsoP: $\mathrm{F}_{2}$-isoprostane; TBARS: thiobarbituric acid reactive substances; $\mathrm{BMI}$ : body mass index; CRF: cardiorespiratory fitness; HbAlc: haemoglobin Alc. ${ }^{* 1} R^{2}=0.014$, adjusted $R^{2}=0.010 ;{ }^{* 2} R^{2}=0.065$, adjusted $R^{2}=0.052 ;{ }^{* 3} R^{2}=0.158$, adjusted $R^{2}=0.090$. 
TABLE 8: Stepwise multiple regression analysis of each oxidative stress marker in men.

\begin{tabular}{|c|c|c|c|c|c|}
\hline & $\begin{array}{l}\text { Partial regression } \\
\text { coefficient }\end{array}$ & $\begin{array}{l}95 \% \text { confidence } \\
\text { interval }\end{array}$ & $\begin{array}{c}\text { Standard partial regression } \\
\text { coefficient }\end{array}$ & VIF & $P$ value \\
\hline \multicolumn{6}{|l|}{$P C^{* 1}$} \\
\hline Intercept & 2.108 & $1.724-2.491$ & & & $<0.001$ \\
\hline $\begin{array}{l}\text { Anti-inflammatory } \\
\text { medication }\end{array}$ & 0.556 & $0.161-0.003$ & 0.11 & 1.00 & 0.006 \\
\hline Age (years) & -0.010 & $-0.016-0.121$ & -0.12 & 1.05 & 0.006 \\
\hline VFA $\left(\mathrm{cm}^{2}\right)$ & 0.002 & $0.000--0.003$ & 0.08 & 1.05 & 0.046 \\
\hline \multicolumn{6}{|l|}{$F_{2}-I s o P^{* 2}$} \\
\hline- & - & - & - & - & - \\
\hline \multicolumn{6}{|l|}{$T B A R S * 3$} \\
\hline Intercept & 2.647 & $2.075-3.219$ & & & $<0.001$ \\
\hline Antioxidant supplementation & 0.234 & $0.080-0.387$ & 0.12 & 1.98 & 0.003 \\
\hline TG (mg/dL) & 0.001 & $0.000-0.001$ & 0.13 & 1.15 & 0.002 \\
\hline Glucose (mg/dL) & 0.009 & $0.004-0.014$ & 0.23 & 1.29 & $<0.001$ \\
\hline VFA $\left(\mathrm{cm}^{2}\right)$ & -0.002 & $-0.003-0.000$ & -0.11 & 1.05 & 0.011 \\
\hline HbAlc (\%) & -0.180 & $-0.331--0.030$ & -0.14 & 1.01 & 0.019 \\
\hline
\end{tabular}

VIF: variance inflation factor; PC: protein carbonyl; $\mathrm{F}_{2}$-IsoP: $\mathrm{F}_{2}$-isoprostane; TBARS: thiobarbituric acid reactive substances; VFA: visceral fat area; TG: triglycerides; glucose: fasting blood glucose; HbAlc: haemoglobin Alc. ${ }^{* 1} R^{2}=0.029$, adjusted $R^{2}=0.024 ;{ }^{* 2} R^{2}=0.043$, adjusted $R^{2}=0.033$; ${ }^{* 3} R^{2}=0.064$, adjusted $R^{2}=0.056$.

associated with resting oxidative stress would be important in prioritising future redox control strategies. Therefore, the present study attempted to identify and weigh the determinants of resting oxidative stress using data from a variety of variables that include objectively measured physical fitness.

The results of the present study revealed that the regression equations of all participants were significant (PC: $P=$ 0.001, $\mathrm{F}_{2}$-IsoP: $P=0.036$, and TBARS: $P=0.004$, respectively), but the regression coefficients $R^{2}$ were small $\left(\mathrm{PC}=0.018, \mathrm{~F}_{2}\right.$-IsoP $=0.006$, and TBARS $\left.=0.071\right)$, revealing low predictive accuracy (Table 6). Consistent with the results of all participants, the subgroup analyses conducted separately for men and women obtained roughly similar results (Tables 7 and 8). Focusing on the previous studies, to the best of our knowledge, there are seven papers that have examined the determinants of resting oxidative stress [4-7, 12-14]. In summary, oxidative stress markers such as TBARS, $\mathrm{F}_{2}$-IsoP, 4-hydroxynonenal bound to thiol proteins (4HNE-P), 8hydroxydeoxyguanosine, and hydrogen peroxidase production have been measured using biological samples such as plasma, erythrocyte and leukocyte lysates, and urine. In addition, the age of the participants ranged from 19 to 88 years, and the number of participants varied widely from 61 to 2828. Furthermore, age, sex, anthropometric index, lifestyle-related parameters (including exercise habits), medication and supplementation status, biochemical parameters, and nutritional intake status were included as independent variables. In these previous studies, the adjusted $R^{2}$ of the regression models ranged from 0.024 to 0.569 [4-7, 12-14]. Compared to these results, the prediction accuracy of each regression model in this study appears to be relatively low (adjusted $R^{2}=0.006-0.071$ ).
Of the previous studies that have examined the determinants of oxidative stress, only three have used plasma as a biological sample $[5,12,14]$. Trevisan et al. examined the determinants of plasma TBARS levels in 1797 men and women aged 35-79 years using multiple regression analysis and reported that gender, plasma glucose, TG, and HDL-C were each associated with the TBARS level [12]. In addition, a study of 298 healthy men and women aged 19-78 years by Block et al. suggested that sex, race, BMI, smoking status, plasma ascorbic acid, $\gamma$-tocopherol, $\beta$-carotene, C-reactive protein, and total- $C$ were determinants of plasma TBARS and/or $\mathrm{F}_{2}$-IsoP levels [5]. Furthermore, a previous study of 61 men and women with heart failure by Asselin et al. showed the involvement of BMI, medication status, blood pressure, blood linoleic acid, HDL-C, total bilirubin, reduced glutathione/oxidized glutathione ratio (GSH/GSSG ratio), glucose, alkaline phosphatase, and myeloperoxidase as determinants of plasma 4HNE-P and TBARS levels [14]. Taken together, this limited evidence suggests that variables such as sex, race, BMI, smoking status, blood pressure, medication status, and biochemical parameters can partially explain resting oxidative stress levels. In addition to these variables, age, leg extension power, CRF, and antioxidant supplementation status were significantly associated with oxidative stress markers in the present study (Table 6). However, the variables selected in the present study can only explain less than $10 \%$ of oxidative stress at rest, even though they are partially consistent with those of previous studies $[5,12,14]$.

The discrepancy in prediction accuracy between previous studies and the present study may be due to differences in the study conditions, such as the target population, the oxidative stress markers selected (i.e., PC, $\mathrm{F}_{2}$-IsoP, TBARS, 4HNE-P, and hydrogen peroxide production), and the methods of 
measuring oxidative stress (e.g., spectrophotometry and high-performance liquid chromatography analysis). However, it is difficult to identify a clear reason for the difference in prediction accuracy. Therefore, further research into the determinants of resting oxidative stress is necessitated.

\section{Conclusions}

This study identified several lifestyle and biological variables that determine resting oxidative stress in middle-aged and elderly men and women and the contribution of independent variables to each oxidative stress marker. However, the present study showed that anthropometric index, lifestyle-related parameters, medication and supplementation status, objectively measured physical fitness, biochemical parameters, and nutritional intake status explain less than $10 \%$ of oxidative stress levels at rest.

\section{Data Availability}

The measurement data of all participants used to support the findings of this study are available from the corresponding author upon request.

\section{Conflicts of Interest}

The authors declare that there are no conflicts of interest regarding the publication of this paper.

\section{Acknowledgments}

We would like to thank all the staff at WASEDA'S Health Study and everyone who participated in the experiment. We would also like to thank Editage (https://www.editage .jp/) for English language editing. This research was supported by Grants-in-Aid for Scientific Research (No. 19H04008) from the Japan Society for the Promotion of Science; MEXT-Supported Program for the Strategic Research Foundation at Private Universities, 2015-2019, from the Ministry of Education, Culture, Sports, Science and Technology (S1511017); and Grant for Special Research Projects (2019C-370) from Waseda University. This project is a collaborative research project with the Institute of Stress Science, Public Health Research Foundation.

\section{References}

[1] T. Finkel and N. J. Holbrook, "Oxidants, oxidative stress and the biology of ageing," Nature, vol. 408, no. 6809, pp. 239247, 2000.

[2] H. Sies, "Oxidative stress: a concept in redox biology and medicine," Redox Biology, vol. 4, pp. 180-183, 2015.

[3] I. Liguori, G. Russo, F. Curcio et al., "Oxidative stress, aging, and diseases," Clinical Interventions in Aging, vol. 13, pp. 757-772, 2018.

[4] N. Sakano, D.-H. Wang, N. Takahashi et al., "Oxidative stress biomarkers and lifestyles in Japanese healthy people," Journal of Clinical Biochemistry and Nutrition, vol. 44, no. 2, pp. 185-195, 2009.
[5] G. Block, M. Dietrich, E. P. Norkus et al., "Factors associated with oxidative stress in human populations," American Journal of Epidemiology, vol. 156, no. 3, pp. 274-285, 2002.

[6] J. F. Keaney, M. G. Larson, R. S. Vasan et al., "Obesity and systemic oxidative stress," Arteriosclerosis, Thrombosis, and Vascular Biology, vol. 23, no. 3, pp. 434-439, 2003.

[7] K. Fujita, H. Nishizawa, T. Funahashi, I. Shimomura, and M. Shimabukuro, "Systemic oxidative stress is associated with visceral fat accumulation and the metabolic syndrome," Circulation Journal, vol. 70, no. 11, pp. 1437-1442, 2006.

[8] M. E. Inal, G. Kanbak, and E. Sunal, "Antioxidant enzyme activities and malondialdehyde levels related to aging," Clinica Chimica Acta, vol. 305, no. 1-2, pp. 75-80, 2001.

[9] P. Gianni, K. J. Jan, M. J. Douglas, P. M. Stuart, and M. A. Tarnopolsky, "Oxidative stress and the mitochondrial theory of aging in human skeletal muscle," Experimental Gerontology, vol. 39, no. 9, pp. 1391-1400, 2004.

[10] G. Block, C. D. Jensen, J. D. Morrow et al., “The effect of vitamins $\mathrm{C}$ and $\mathrm{E}$ on biomarkers of oxidative stress depends on baseline level," Free Radical Biology and Medicine, vol. 45, no. 4, pp. 377-384, 2008.

[11] D. Zapolska-Downar, M. Naruszewicz, A. Zapolski-Downar, M. Markiewski, H. Bukowska, and B. Millo, "Ibuprofen inhibits adhesiveness of monocytes to endothelium and reduces cellular oxidative stress in smokers and non-smokers," European Journal of Clinical Investigation, vol. 30, no. 11, pp. 1002-1010, 2000.

[12] M. Trevisan, R. Browne, M. Ram et al., "Correlates of markers of oxidative status in the general population," American Journal of Epidemiology, vol. 154, no. 4, pp. 348-356, 2001.

[13] K. Yasunari, K. Maeda, M. Nakamura, and J. Yoshikawa, "Oxidative stress in leukocytes is a possible link between blood pressure, blood glucose, and C-reacting protein," Hypertension, vol. 39, no. 3, pp. 777-780, 2002.

[14] C. Asselin, A. Ducharme, T. Ntimbane et al., "Circulating levels of linoleic acid and HDL-cholesterol are major determinants of 4-hydroxynonenal protein adducts in patients with heart failure," Redox Biology, vol. 2, no. 1, pp. 148155, 2014.

[15] S. K. Powers, A. J. Smuder, A. N. Kavazis, and M. B. Hudson, "Experimental guidelines for studies designed to investigate the impact of antioxidant supplementation on exercise performance," International Journal of Sport Nutrition and Exercise Metabolism, vol. 20, no. 1, pp. 2-14, 2010.

[16] A. S. Veskoukis, A. Kyparos, V. Paschalis, and M. G. Nikolaidis, "Spectrophotometric assays for measuring redox biomarkers in blood," Biomarkers, vol. 21, no. 3, pp. 208-217, 2016.

[17] J. N. Cobley, G. L. Close, D. M. Bailey, and G. W. Davison, "Exercise redox biochemistry: conceptual, methodological and technical recommendations," Redox Biology, vol. 12, pp. 540-548, 2017.

[18] S. Kobayashi, K. Murakami, S. Sasaki et al., "Comparison of relative validity of food group intakes estimated by comprehensive and brief-type self-administered diet history questionnaires against $16 \mathrm{~d}$ dietary records in Japanese adults," Public Health Nutrition, vol. 14, no. 7, pp. 1200-1211, 2011.

[19] S. Kobayashi, S. Honda, K. Murakami et al., "Both comprehensive and brief self-administered diet history questionnaires satisfactorily rank nutrient intakes in Japanese adults," Journal of Epidemiology, vol. 22, no. 2, pp. 151-159, 2012. 
[20] C. Usui, R. Kawakami, K. Tanisawa et al., "Visceral fat and cardiorespiratory fitness with prevalence of pre-diabetes/diabetes mellitus among middle-aged and elderly Japanese people: WASEDA'S Health Study," PLoS One, vol. 15, no. 10, article e0241018, 2020.

[21] A. B. Salmon, A. Richardson, and V. I. Pérez, "Update on the oxidative stress theory of aging: does oxidative stress play a role in aging or healthy aging?," Free Radical Biology and Medicine, vol. 48 , no. 5, pp. 642-655, 2010. 